\title{
artículos
}

\section{Juan Monserrat Vergés: masonería y arquitectura en Granada. El ejemplo del Buen Suceso**}

David Martín López

Universidad de Granada

PALABRAS CLAVE: Masonería/ Arquitectura Contemporánea/ Granada

\section{RESUMEN}

El s. XIX en Granada fue propicio para la consolidación del carácter filantrópico de la masonería. Numerosas logias se crearon en la provincia, cifrándose en 475 sus miembros en la ciudad. Este artículo pretende ser una aproximación a uno de los arquitectos masones más relevantes de este período, Juan Monserrat. El Arzobispado, la Universidad y el Ayuntamiento de Granada, fueron algunos de sus comitentes institucionales. También realizaría obras para la burguesía granadina como los Rodríguez-Acosta. El ejemplo presentado es el de una casa de estética masónica, obra paradigmática que repercutirá en la construcción de la Gran Vía de Colón.

\section{ABSTRACT}

In the Nineteenth century, Grenade was an appropriate place for the consolidation of the philanthropic side of Masonry. Several lodges were created in the province, counting in 475 members in the city. The aim of this paper is to present one of the most relevant mason architects of this period: Juan Monserrat. The Archbishopric, The University and the Council of Grenade were some of his institutional sponsors. In addition to this, he also made several constructions for some members of the grenadian's bourgeoisie, such as Rodriguez-Acosta's family. This featuring issue is a Masonic's esthetical building, one of the paradigmatic references in the construction of Gran Vía de Colón's Avenue.

Granada a finales del s. XIX experimenta un proceso transformador y regenerador en muchos de sus ámbitos sociales, tanto económicos como culturales y políticos. Y es que el inicio de la centuria del s. XIX había marcado el comienzo de una decadencia. A Granada "[...] languidecente y ensimismada, pálido reflejo de lo que había sido, le quedará, sólo, esa aureola de ciudad encantada que exaltó la fantasía

* MARTÍN LÓPEZ, David: "Juan Monserrat verges: masonería y arquitectura en Granada, el ejemplo de Buen Suceso", Boletín de Arte, n²8, Departamento de Historia del Arte, Universidad de Málaga, 2007, págs.173189. 
de los románticos del siglo que se refugiaron en ella, física o imaginariamente, y ensalzaron y difundieron su fama y su imagen utilizando como vehículos la pintura, la poesía, la literatura o la música"1.

La estancia de los franceses en la ciudad, había arruinado muchos sectores económicos como la propia industria granadina. A mediados del s. XIX ésta se recuperaba paulatinamente, contando con siete fundiciones de plomo y tres de hierro. Los negocios azucareros se iban a iniciar en 1868, destacando la participación de Juan Ramón la Chica, José María Rodríguez y José González Aurioles ${ }^{2}$. En buena medida, este cambio económico que se produce desde mediados del siglo, estuvo propiciado por las nuevas explotaciones agrícolas, el auge de la caña de azúcar o la industrialización de La Vega y la costa granadina, provocando un despertar absoluto del letargo económico dieciochesco. La ciudad se convertía así, en una urbe más de España, que se adentraba -paulatinamente- en el desarrollo de toda capital de provincia. La arquitectura contribuyó con las nuevas tendencias estilísticas finiseculares a crear esa nueva imagen de la capital granadina.

Este acontecimiento exclusivamente económico -en principio-, genera una serie de reformas y ampliaciones urbanísticas en el casco antiguo de la ciudad, como pueden ser los planteamientos de la Gran Vía de Colón u otras racionalizaciones del espacio y de la urdimbre urbana, dejando atrás el aspecto medieval-musulmán que tenía la ciudad hasta el s. XIX, subrayando el concepto de una ciudad nueva, abierta al ocio y al esparcimiento, algo propuesto ya por las directrices francesas del general Sebastiani -tras su entrada el 28 de febrero de 1810-3; algo que por otro lado suplía las necesidades de las que carecía la ciudad -higiene, regularización del tránsito, seguridad y ornato público-. La Gran Vía y los nuevos espacios de la urdimbre urbana situados junto al río Genil -Carrera de La Virgen, Paseo de La Bomba, Paseo de La Alameda y Paseo del Violón-, así como la construcción de espacios públicos en terrenos exclaustrados como el Convento de la Trinidad -que se convertiría en la plaza homónima en 18954 - son las nuevas soluciones que el entramado urbano daría a la ciudad para satisfacer las necesidades de la población. Ángel Ganivet tachaba

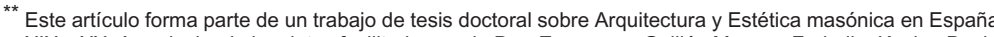
s. XIX y XX. Agradeciendo los datos facilitados por la Dra. Esperanza Guillén Marcos, Federike Koch y David García Cueto; y al Archivo Municipal de Granada, por las aportaciones realizadas y el acceso al estudio directo sobre las fuentes.

1 CAPARRÓS MASEGOSA, L: Artes plásticas en la prensa granadina del siglo XIX. Granada, Universidad de Granada -Biblioteca de Arte y Arqueología-, 2001, pág. 19.

2 GAY ARMENTEROS, J.; VIÑES MILLET, C.: Historia de Granada. IV. La época contemporánea. Granada, Editorial Quijote, 1982, págs. 27-28.

3 GAY ARMENTEROS, J.: Granada Contemporánea. Breve historia. Granada, Editorial Comares, 2001, pág. 31.

${ }^{4}$ ANGUITA CANTERO, R.: La ciudad construida. Control municipal y reglamentación edificatoria en la granada del s. XIX. Granada, Diputación Provincial de Granada, 1997, pág. 127. 
Q artículos Juan Monserrat Vergés: Masonería y arquitectura...

de locura diabólica lo que la ciudad estaba experimentando: "[...] a Granada ha llegado la epidemia del ensanche y como no había razón para que nos ensancháramos porque teníamos nuestros ensanches naturales... y más nos sobraba población, concebimos la idea famosa de ensancharnos por el centro y el proyecto diabólico de destruir la ciudad $[\ldots]^{\prime \prime}$.

Al mismo tiempo, como signo propio de toda época de esplendor o despertar burgués asociado a la era industrial, se remozarán las fachadas de las casas de principios del s. XIX y de aquellas antiguas mansiones del s. XVIII, confiriéndoles ahora una imagen romántico-clasicista en muchas ocasiones, llegando -incluso- a gestarse verdaderos "fachadismos" eclécticos, modernistas, o de cierto resabio historicista, de acorde a los nuevos parámetros estéticos de la ciudad, como sería el planteamiento de fachada del desaparecido Convento del Ángel Custodio, proyectado bajo pautas neorrománicas según dibujo de Francisco Prieto Moreno y Velasco en $1908^{6}$ o las reformas efectuadas por Juan Monserrat Vergés en la Facultad de Derecho, con el ecléctico torreón-observatorio y el enverjado del Jardín Botánico.

Si bien, se estaba produciendo un movimiento regenerador en el urbanismo granadino, "la ciudad se encontraba en 1910 con 1.000 edificios menos de los que había tenido cincuenta años atrás [...] en todo este tiempo habían faltado los medios necesarios para renovar el parque de viviendas, ya que el número de habitantes había aumentado ligeramente desde 67.326 habitantes en 1859 hasta 72.802 en $1810 " 7$.

Un arquitecto masón en Granada: Juan Monserrat Vergés.

No es el momento de comentar -en este texto-, la importancia que tuvo la masonería en España en el s. XIX8. Sin embargo, debemos señalar en pocas líneas cómo Granada sería un importante núcleo filantrópico de Andalucía Oriental en el período de nuestro análisis. Andalucía, en el último tercio del s. XIX, como comenta

5 Cita de Ángel Ganivet recogida en el "Estudio introductorio" de J. Bosque Maurel en la edición facsímil del Diccionario Geográfico-estadístico-Histórico de España y sus posesiones de ultramar de F. Madoz Granada, 1987-, extraído de CAPARRÓS MASEGOSA, L.: Op. Cit., pág. 28.

${ }^{6}$ Aunque ya se había efectuado con anterioridad una readaptación de fachada -no historicista- hacia la calle Barrecheguren por Juan Monserrat Vergés en 1899. Cfr. alzados en BARRIOS ROZÚA, J. M.: La Granada desaparecida. Granada, Editorial Comares, 1999, págs. 256-257.

7 MARTIN RODRÍGUEZ, M.: La Gran Vía de Granada. Cambio económico y reforma interior urbana en la España de la Restauración. Granada, Caja General de Ahorros y Monte de Piedad, 1986, pág. 175

${ }^{8}$ Es en Budapest, en la Enciklopedio de Esperanto -1933-, donde se daba -quizás- la definición más correcta, al menos con lo que respecta a los fines precursores de la masonería, en consonancia con su carácte durante el s. XIX: "Comunidad de hombres que piensan libremente, unidos en logias. Su origen se halla en los gremios medievales de los albañiles. La construcción se entiende en sentido moral. Su Constitución es de 1723, escrita por Anderson. Frecuentemente atacados, debido a consideraciones políticas y religiosas". PAZ SÁNCHEZ, M.; CARMONA CALERO, E.: Canarias: La Masonería. Tenerife, Centro de la Cultura 
José A. Ferrer Benimeli, contó con al menos 435 logias, duplicando en cantidad a las cubanas, madrileñas o catalanas. En este periodo finisecular, más de 700 masones tuvo Granada como provincia ${ }^{9}$. Para el caso de la masonería granadina de finales de ese siglo, la historiografía cuenta con numerosos estudios científicos realiza$\operatorname{dos}^{10}$, que constatan la pertenencia de numerosas personalidades del ámbito universitario y de la enseñanza secundaria ${ }^{11}$, políticos, grandes hacendados, artistas y arquitectos.

Juan Monserrat Vergés -arquitecto masón de origen catalán-12, fue uno de los personajes más activos de la vida cultural y artística de la Granada finisecular. Estuvo becado en la Academia Española de Bellas Artes en Roma, donde se conserva un autorretrato suyo ${ }^{13}$. A su llegada a Granada, Monserrat, ostentaría los cargos institucionales de Arquitecto municipal de Granada, Arquitecto de la Diócesis de Granada y el de Arquitecto diocesano de Guadix-Baza14, así como otros cargos puntuales como arquitecto de la Universidad de Granada, además de arquitecto inspector de Hacienda para el Registro de Edificaciones y Solares.

1877 sería una fecha clave para su biografía. En abril se había hecho cargo

Popular Canaria (CCP), 1996, págs. 11-12. Al respecto, el fundador de la logia Fraternidad $n^{\circ} 887$ de Nueva York y Grado 33, A. Cassard, afirmaba en su obra El espejo Masónico, editada en Nueva York en 1866, que la masonería "[...] no es puramente una asociación filantrópica para proporcionar auxilios mutuos y dispensar a los necesitados de los favores de la caridad. No es tampoco un sistema de clubs o reorganización polí ticos que se apelliden conservadores, radicales o revolucionarios. No se distingue ni por la máscara del carbonario ni por la sotana del jesuita ni por la capucha del inquisidor. No es una orden religiosa... ni tampoco una sociedad antirreligiosa para combatir determinadas creencias. La Masonería no es un apóstol de ninguna forma particular de gobierno, ni defensor de ningún credo político. Es el apóstol, el propagador y defensor de la verdad [...]"-PINTO MOLINA, M.: La masonería en Málaga y su provincia. Ultimo tercio del s. XIX. Granada, Universidad de Granada, 1986, pág. 9-. Con esta idea tan extensa de lo que no pretende ser la la Verdad. Esta idea sería el nexo también que unía a los masones granadinos, cuyos talantes políticos, culturales y económicos eran muy diversos.

9 LÓPEZ CASIMIRO, F.: Los masones en Granada. Granada, Editorial Comares, 2001, pp. XIII-XV.

10 El Dr. Juan Gay Armenteros, el Dr. Eduardo Enríquez del Árbol, la Dra. María Pinto Molina y el Dr. Francisco López Casimiro han abordado distintos aspectos de la masonería en Andalucía Oriental, analizando cuestiones históricas, políticas, sociales y culturales de la misma.

11 Ferrer Benimeli señala que más de 31 masones granadinos se dedicaron a la educación, tanto en el ámbito universitario como en el de los Institutos de Enseñanza Secundaria. LOPEZ CASIMIRO, F.: Op. cit., pág. $\mathrm{XV}$.

12 JEREZ MIR, C.: Guía de Arquitectura de Granada. Granada, Editorial Comares, 2003, pág. 280.

13 La serie de retratos de los becarios de la Academia de Bellas Artes de España en Roma comienza en 1881. Por esas fechas, nuestro arquitecto trabajaba en España, concretamente en Granada. El retrato -muy probablemente- sería realizado a posteriori de su estancia como becario y enviado a Roma. RINCÓN GARCÍA, W.: "El autorretrato: ensayo de una teoría" en El autorretrato en la pintura española: De Goya a Picasso, Catálogo de la Exposición homónima. Madrid, Fundación Cultural Mapfre Vida, 1991, pág. 27.

14 Juan Monserrat Vergés es nombrado Arquitecto de la Diócesis de Guadix-Baza y de Granada en 1877, ocupando el cargo en Guadix-Baza hasta 1888, fecha en la que renuncia; un año más tarde hará lo mismo con el cargo de arquitecto diocesano del Arzobispado de Granada. RODRIGGUEZ DOMINGO, J. M.: "La Junta de Reparación de la Diócesis de Guadix-Baza (1845-1904)". En Cuadernos de Arte, n 31. Granada, Editorial Universidad de Granada, 2000, págs. 159-175. 
de las importantes reformas del edificio central de la Universidad, y el 15 de diciembre de ese mismo año, es nombrado arquitecto de la Diócesis de Guadix-Baza y del Arzobispado de Granada ${ }^{15}$. Para la Universidad realizaría numerosos proyectos, destacando las reestructuraciones y ampliaciones del Palacio de Derecho, modificando el proyecto de Santiago Baglietto16 y la Facultad de Medicina en $1882^{17}$. Baglietto había sido el primer responsable de las reformas de ampliación de la Universidad, pero tras morir éste, Juan Pugnaire toma el cargo en marzo de 1876 quien diseñó la fachada del Jardín Botánico por la Calle Duquesa-, dimitiendo por problemas de salud en octubre de ese mismo año. El encargado sería ahora Juan Monserrat Vergés, aceptando el puesto de arquitecto de la Universidad en abril de 1877. Hasta 1886, se encuentra ejecutando reformas en la Universidad, en la escalera principal y los patios destinados a albergar unas nuevas aulas y un museo. Además, en 1887 presenta la proyección de un invernadero en el Botánico de la Universidad, así como de la terminación del cerramiento del mismo -en las calles de Las Escuelas y Málaga-18 y el Proyecto de Instalación de Para-rayos, teléfonos y Timbres eléctricos en la Universidad Literaria de Granada19.

Nuestro arquitecto no sólo ocupó estos nombramientos públicos, sino que, al mismo tiempo, compaginó su actividad artística con la filantrópica dentro de las logias granadinas. Juan Monserrat Vergés formaría parte del primer cuadro lógico de la logia Beni-Garnata $n^{\circ} 178$ de 10 de febrero de 1883, año de su fundación, junto a los veinticinco miembros restantes. Adoptaría el nombre simbólico de Ictinuis, en relación a uno de los grandes arquitectos de la Historia, autor del Partenón ateniense. Juan Gay Armenteros y María Pinto Molina señalan que la fecha de iniciación de todos sus miembros, exceptuando uno en 1880 y otro en 1882, era la de 188320.

En 1885 llega a ser Tesorero21. Esta logia suponía uno de los centros masónicos más destacados de Granada. Al respecto, el Gran Oriente resalta el carácter ilustrado de sus hermanos, afirmando que "[...] siempre fue Granada cuna de grandes ingenios y no en vano la llama de la Historia, la Atenas de la Francmasonería"22. En 1886, Monserrat ya contaba con el grado 13. Tres años más tarde, aparecía

\footnotetext{
15 RODRÍGUEZ DOMINGO, J. M.: Op. Cit., págs. 159-175.

16 GALLEGO Y BURÍN, A.: Op. Cit., pág. 277.

17 AAVV: Universidad y Ciudad. La Universidad en la historia y la cultura de Granada. Granada, Universidad de Granada, 1994, págs. 159-161.

18 FERNANDEZ-CARRIÓN, M., GARCÍA MONTES, J. M.: MOLERO MESA, J.: El jardín botánico de la Universidad de Granada. Granada, Universidad de Granada, 1993, págs.63-75.

19 AAVV: Op. Cit., págs. 120-127.

20 GAY ARMENTEROS, J.;PINTO MOLINA, M.: La Masonería en Andalucía Oriental a fines del siglo XIX. Jaén y Granada. Granada, Universidad de Granada, 1983, págs. 330-331.

21 Ibídem., pág. 311.

22 Ibídem, págs. 298-299.
} 
como Tesorero del Capítulo Provincial, órgano superior que reunía a las logias granadinas. Por aquel entonces, nuestro arquitecto era representante de la logia Luz del Porvenir núm. 179 de Loja, contando con grado 20 en la masonería ${ }^{23}$. Al año siguiente, Monserrat Vergés formaba parte del Consejo Areopágico Mariana Pineda, la célula masónica de Granada capital, pues el taller abarcaba del grado 19 al 30, grados filosóficos de la masonería negra. Contaba con doce miembros en 1890, siendo Juan Monserrat Vergés el Gran Tesorero 24 y además el Presidente del Capítulo Provincial 25 .

En 1890 trabajaban dos logias del Gran Oriente Nacional de España (GONE), la Alianza de 1817 núm. 112 y la Logia Beni-Garnata núm. 178. Sin embargo se constituye una nueva logia del GONE con el nombre de Granada núm. 273. A la inauguración del templo acudieron con gran solemnidad representaciones de todos los capítulos y las logias del Gran Oriente, particularmente a los de Granada. "Nombró a Jorge Lombarte presidente de la comisión instaladora, a los venerables de las logias Alianza de 1817 y Beni-Garnata, miembros de la misma, y a Juan Monserrat, presidente del Capítulo Provincial, 'en representación de la Logia Madre de la Francmasonería española, La Matritense núm. 1"'26.

Aparte de los cargos públicos e institucionales en la masonería, también sería miembro fundador del Centro Artístico, Literario y Científico de Granada ${ }^{27}$, así como contable de la Sociedad obrera La Obra. Esta asociación, con marcado carácter filantrópico, pretendía promover la educación, la instrucción y cultura de la clase obrera, así como el mejoramiento económico de la misma, tal y como se señala en el artículo $1^{\circ} \mathrm{de}$ su Reglamento. En ella, se reunían trabajadores e intelectuales masones. De las nueve personas que redactaron el reglamento de La Obra, cinco eran masones. A los cuatro meses de su fundación, los socios eran $4.088^{28}$.

En este ambiente granadino de transmutación de la ciudad finisecular, son varios los arquitectos masones que trabajarán en ella. $Y$ es que el corporativismo artístico de la masonería hacía que buena parte de las producciones arquitectónicas cuyos comitentes eran masones se encontraran construidas por arquitectos hermanos. En toda la España contemporánea, el panorama era similar ${ }^{29}$. Monserrat Vergés

23 LÓPEZ CASIMIRO, F.: Los masones en Granada. Último tercio del s. XIX. Granada, Editorial Comares, 2000, págs. $257-258$

24 Ibídem, págs. 262-265.

25 GAY ARMENTEROS, J.; PINTO MOLINA, M.: Op. Cit., págs. 346-347.

26 LÓPEZ CASIMIRO, F.: Op. Cit., págs. 145-150.

27 Para una información más detallada de la participación de la masonería en la vida del Centro Artístico y en la cultura granadina, cfr. LÓPEZ CASIMIRO, F.: "Masonería y cultura (A propósito del Centro Artístico de Granada)". En Actas XI Congreso Hespérides, 1993, págs. 379-384.

28 GAY ARMENTEROS, J. y PINTO MOLINA, M.: Op. Cit., págs. 391-393.

29 Este es el caso también de Santa Cruz de Tenerife -desde 1890 a 1937, aproximadamente-, donde la 

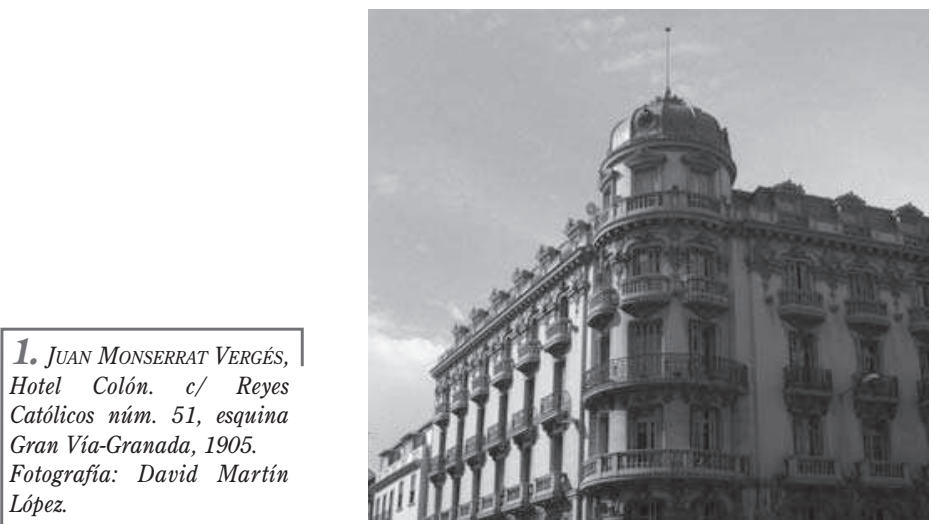

era por tanto el "arquitecto de moda" de la burguesía granadina; bien podía proyectar iglesias como la parroquial de Gabia La Grande en $1887^{30}$ o edificios públicos como el Hotel Colón [1], la Banca Rodríguez Acosta ${ }^{31}$, el Edificio del Servicio Doméstico, colegios, industrias, y -como arquitecto municipal- desarrollando las nuevas soluciones y necesidades urbanísticas de la ciudad: calles, saneamiento, plazas, fuentes, obras importantes en el Cementerio Municipal, la Pescadería del Mercado Municipal en 1884 , etc. 32 .

En la disciplina urbanística, cabe destacar su especial participación en la reestructuración de la zona del Convento de la Trinidad, tras el comienzo de su derribo en 1884, y su inmediata paralización con el consiguiente vertedero de escombros. El Ayuntamiento consultaría a Juan Monserrat Vergés como arquitecto municipal,

masonería era muy significativa en las esferas políticas e intelectuales. Su corporativismo, como red de conexiones, hizo afirmar al arquitecto almeriense José Blasco Robles que, desde su llegada -en 1928- había recibido "[...] numerosas proposiciones de logias tinerfeñas, “...comprobando que la mayoría de las personalidades políticas locales y en general los profesionales tenían algunas relaciones con las logias masónicas'[...]"-MARTíN LÓPEZ, D.: “José Blasco Robles (1904-1996). Un racionalista velezano en Canarias", en Revista Velezana, $n^{\circ} 23$. Almería, Ayuntamiento de Vélez Rubio y Diputación de Almería, 2004, págs. 133140-. Cfr. NAVARRO SEGURA, M.: El racionalismo en Canarias. Tenerife, Aula de Cultura del Excmo. Cabildo Insular de Tenerife, 1987.

30 GUILLÉN MARCOS, E.: "La iglesia de Gabia La Grande y los historicismos medievalistas en la arquitectura religiosa granadina”. En CIRICI NÁRVAEZ, J. R. y ANTIGÜEDAD DEL CASTILLO-OLIVARES, M. D. (coord. y ed.): Arquitectura y ciudad en España. De 1845 a 1898. Servicio de Publicaciones de la Universidad de Cádiz, Cádiz, 2000, págs. 57-63.

31 JEREZ MIR, C.: Op. Cit., pág. 302.

$32 \mathrm{Al}$ respecto debemos señalar que Monserrat realiza numerosas obras en Granada, algunas de ellas con distintas adjudicaciones de autoría. Este es el problema que planteado en la historiografía, al atribuirle Antonio Gallego y Burín, la autoría de la neogótica Iglesia del Sagrado Corazón de Jesús y la Residencia de los Padres Jesuitas de la Gran Vía, construida en 1910. GALLEGO Y BURÍN, A.: Granada. Guía artística e histórica de la ciudad. Granada, Editorial Comares, 1996, pág. 322 
para elaborar una posible solución a la zona afectada, puesto que el problema generaría distorsiones en el ornato público y en las operaciones urbanísticas de la misma. Escribe un informe donde cree necesario "[...] llamar la atención a la Corporación municipal sobre la conveniencia de prolongar la calle del Buen Suceso desde la Alhóndiga hasta la de Mesones y trazar una nueva alineación en la placeta de la Trinidad, haciendo que sea la prolongación de la línea de la calle Capuchinas, con lo cual se conseguiría una ampliación de la vía pública y una mejora tanto para el tránsito público como para el embellecimiento de esta ciudad"33.

Embellecer la ciudad, tal y como Monserrat Vergés señala en su informe, es el afán que como arquitecto efectúa en Granada durante varias décadas, con su rico bagaje cultural y la amplia visión arquitectónica de las soluciones vistas en sus estancias en Roma y Madrid, así como sus conocimientos sobre ingeniería y telecomunicaciones elaborados por la Academia de París 34 .

Sus tendencias estilísticas oscilan desde los rigurosos historicismos, pasando por los neomudéjares, eclecticismos, neogóticos ingleses, modernismos y soluciones de cierto gusto francés, entre otras. Sus ocupaciones como arquitecto municipal y diocesano de Granada a finales del s. XIX le hicieron dimitir de su cargo de Arquitecto de la Diócesis de Guadix-Baza en 1888. A instancias del propio Monserrat, su cargo lo delegaba en José Ladislao Abásolo, arquitecto que trabajaba en Granada y que también era hermano de la logia Beni-Garnata. núm. 178 a la que Juan Monserrat Vergés pertenecía. Un año más tarde, renuncia también como arquitecto del Arzobispado, siendo sustituido también por Ladislao Abásolo 35 .

La casa de Buen Suceso: aproximación la estética masónica en GRANADA.

Juan Monserrat Vergés a principios del s. XX, había abandonado hacía tiempo el cargo de arquitecto municipal, centrándose sólo en sus ocupaciones artísticas y filantrópicas, y siendo -como consta en 1903, en el Archivo de la Real Chancilleríael arquitecto al servicio de Hacienda, para realizar la comprobación técnica de la declaración de alta de las fincas de la Gran Vía en el Registro Fiscal de Edificios y Solares ${ }^{36}$. Desarrollaría ahora una significativa intervención en fachada, en el céntrico Barrio de la Magdalena, en una casa de la calle del Buen Suceso, situada trans-

33 ANGUITA CANTERO, R.: Op. Cit., págs. 187-188.

34 Juan Monserrat será el encargado en 1887 de realizar el Proyecto de Instalación de Para-rayos, teléfonos y Timbres eléctricos en la Universidad Literaria de Granada de 1887, con los avances parisinos, citando -reiteradamente-, en un informe facultativo para la instalación del servicio telefónico, las nuevas soluciones y comunicaciones de la Academia de París. AAVV: Op. Cit., pág. 127

35 RODRíGUEZ DOMINGO, J. M.: Op. Cit., págs. 159-175. 
versalmente en el extremo de la calle Puentezuelas, en el tramo que va desde la misma hasta la calle de San Miguel Alta.

Se trata, en concreto, de una reforma en la casa núm. 23 de la calle del Buen Suceso, propiedad de D. Juan Lisbona Beltrán, con fecha -de aprobación del proyecto- de veintisiete de septiembre de 190137. Don Juan Lisbona pide un permiso de reforma de fachada, que entra en el ayuntamiento a dieciocho de septiembre de 1901. El alcalde lo firma a diecinueve, de ese mismo mes, y lo manda a la Comisión de Ornato Público ${ }^{38}$, dirigida por el arquitecto municipal Modesto Cendoya, quien da el visto bueno, a la "[...] reforma de fachada con apertura de huecos y modificación de otras en beneficio del ornato público [...]" por ser en "[...] beneficio del ornato público, por lo que y teniendo en cuenta que la casa no está sujeta a nueva alineación"39.

El proyecto que D. Juan Lisbona había presentado, tenía dos alzados a escala 1:100: el estado que tenía la casa -en esos momentos- y el que Monserrat iba a efectuar, firmado a 17 de septiembre de 1901. La casa aparecía en su alzado inicial con medidas de vanos y alturas de sus plantas, pareciendo haber sido reformada o construida en el s. XVIII. Ésta tiene 3 cuerpos, con la forma granadina del altilloalpendre a la manera de logia de seis arcos.

El plano del proyecto que se adjunta respetaba las anteriores alturas de la casa siendo éstas: 3’70 m. 3'65 m. y 3'70 m. cada planta, en sentido ascendente, respectivamente. Los vanos abiertos no corresponden con los anteriores -totalmente asimétricos-, que tenían gran portalón de 2'70 m. y 1'30 m. de ancho. La puerta principal se centra y se pone de 2'75 m. de altura. Monserrat Vergés, en un estudio minucioso incluso aporta las medidas de los vanos de los balcones de rejería, 2'60 m. de alto y 1'15 metros de ancho. Se mantiene la logia del tercer cuerpo pero se adorna con frisos y pilastras de ladrillo, con un intento de racionalizarla ${ }^{40}$ [2].

\footnotetext{
36 MARTÍN, M.: Op. Cit., pág. 138.

37 El número 23 corresponde a la época de la reforma. En la actualidad ocupa el número 21 de la calle, aunque sigue siendo perceptible el número marmóreo con la anterior marcación. Cfr. Archivo Municipal de Granada (en adelante, AMG). Leg. 1455. Pieza 17. Licencia de obra. c/ Buen Suceso, 23. 27 de Septiembre de 1901. Pieza 17. Expediente "Sobre la licencia de obra en la casa no 23 de la c. del Buen Suceso, propiedad de Dn. Juan Lisbona Beltran".

38 La Comisión de Ornato Público fue restituida en 1837, dotada en 1842 de cuatro arquitectos de ciudad Juan Pugnaire, José Contreras, Salvador Amador y Baltasar Romero- por las importantes necesidades municipales, con "[...] cuatro celadores municipales, uno por cuartel, que habrán de vigilar las posibles infracciones sobre edificación, y que, presentándose por turnos, siempre se encuentre presente un arquitecto de ciudad en las sesiones de la Comisión de Ornato Público"- ANGUITA CANTERO, R,: Op. Cit., págs. 68-71. 39 AMG, Op. Cit.

40 Monserrat Vergés inicialmente sigue las pautas de decoro marcadas por la Real Orden de 9 de Febrero de 1863 sobre la limitación en las obras de consolidación y reforma de los edificios sometidos a alineación. La asimetría que presenta en alzado de fachada la casa hizo atender al punto $5^{\circ}$ de la orden, de manera que
} 


2: artículos David Martin López

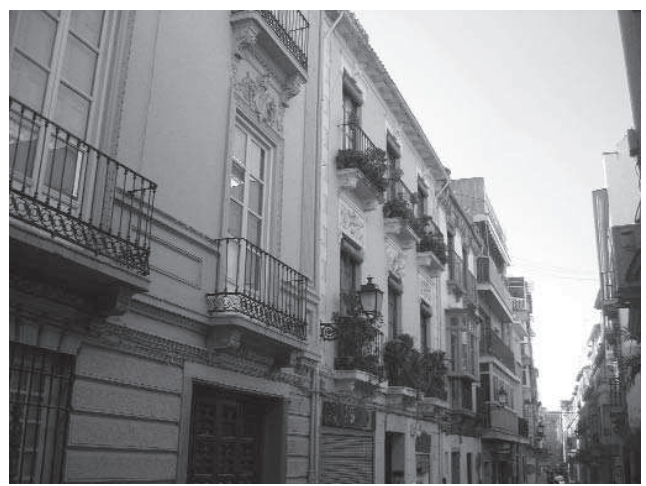

2. JUAN MONSERRAT VERGÉS, Aspecto parcial de la calle Buen Suceso de Granada. Casa de Juan Lisbona -a la derecha, 1901. Fotografía: David Martín López.

Sin embargo Monserrat no legó a ejecutar estrictamente el proyecto de reforma de fachada. Si bien respetaría las tres alturas, la logia la elimina configurando estancias en la tercera planta [3], con ventilación y luminosidad dada por tres balcones, de menor envergadura que los del piano nóbile, aunque bajo ménsulas a modo de canes, que tienen como elemento decorativo la misma solución vegetal de tres flores, apreciable también en otras casas del mismo autor, como en la c/ Niños Luchando, núm. 8.

Juan Monserrat terminaría el edificio tal y como se puede observar en la actualidad. La casa, según su alzado en fachada, consta de tres cuerpos, cada uno de ellos con tres calles y tres vanos, respectivamente por cada uno. Tres puertas en el primer cuerpo -con puerta central diferenciada-, y tres balcones con rejería en los otros dos pisos, sujetados por dos ménsulas, con flores de loto.

En esta residencia es, tal vez, donde quedan más claramente reflejadas las dos facetas de nuestro personaje: la de arquitecto y la de masón. Es decir, en el planteamiento de la reforma, Monserrat Vergés adopta un tipo de fachada, de corte clasicista-romántico en sintonía con la época y con las reestructuraciones edilicias de la ciudad, dejando una solución de reforma menos atrevida, como proponía el propio arquitecto y que hubiera significado la racionalización y simetría del espacio, con la conversión neomudéjar de la logia. No obstante, si bien su proyecto carece de importancia a nivel arquitectónico e incluso estilístico, no sucede así con el sentido estético del mismo, pues inaugura un concepto subversivo de lenguaje masónico, indes-

como señalaba ésta: "Cuando existan huecos de diferentes pisos cuyos centros respectivos no correspondan verticalmente, podrán ser trasladados lo necesario para centrarlos al eje de un hueco existente, elegido a voluntad en cualquier piso"-ANGUITA CANTERO, R.: Op. Cit., pág. 211. 


\section{- artículos Juan Monserrat Vergés: Masonería y arquitectura...}

\section{JUAN MONSERRAT} VERGÉs, Casa de Juan

Lisbona Beltrán -Granada,1901. Fotografia: David Martín López.

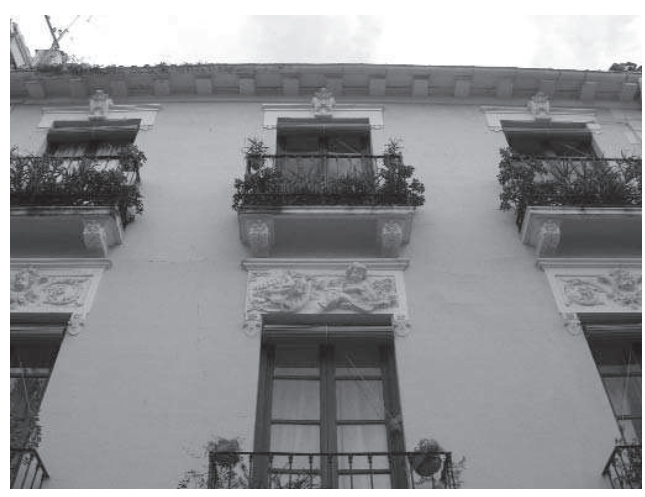

cifrable para la sociedad granadina no iniciada, pero a su vez, toda una declaración de intenciones, no sólo de quien lo realiza sino -posiblemente- también de quien lo vivirá41.

En este sentido, nuestro arquitecto incorpora tres relieves escultóricos en cemento, en la segunda planta del edificio, justo encima da cada vano. Cada puerta de balcón lateral tiene un relieve con una cara de un putti, del que salen dos hojarascas. El de la puerta del balcón central es el que nos ocupa ${ }^{42}$. Éste adopta todos los elementos masónicos más importantes, que a la vez son emblemas propios del oficio de la arquitectura -un putti, el compás ${ }^{43}$, el capitel, el plano, la pluma que se unen a otros más específicos de la maestrías gremiales, y por ende, de la masonería: la maza, la pala, el yunque, la plomada, la escuadra, etc.- 44 , con ramas de lau-

41 Las fuentes consultadas no aseguran la pertenencia del propietario D. Juan Lisbona Beltrán a la masonería granadina del s. XIX. En muchos casos, existen masones que, aunque se encontraran residiendo en una ciudad determinada, estaban adscritos a logias ubicadas en otras ciudades o poblaciones.

42 Juan Monserrat Vergés también insertará altorrelieves en la Facultad de Derecho de la Universidad de Granada. En algunos de estos relieves de cemento que se encuentran en un patio, el arquitecto masón expondrá teorías ético-morales como la representación de El amor sacro que deriva al amor profano. Esón expondá tón relieve está inspirado directamente en un dibujo obra del pintor, grabador y dibujante Giovanni Andrea Podestà, con algunas varaciones en los atibutos de lázquez en Italia. Madrid, Apoyo al Arte hispánico, 2002, pág. 123. pié de lámina 121. El mismo relieve es apreciable también en un inmueble contemporáneo al arquitecto, situado en la madrileña calle Marqués de Urquijo esquina calle Tutor.

43 El compás, realizado con hierro y cemento no ha llegado hasta nuestros días en la calle de Buen Suceso. No obstante, en otros relieves escultóricos idénticos -incluso con las mismas irregularidades que el que nos ccupa presenta en su margen superior izquierdo-, y realizados, con fecha posterior a 1901, por Francisco Giménez Arévalo, en la Gran Vía de Colón, se muestra de la misma manera que hubiera tenido en esta casa. 44 En relación a los elementos que aparecen no pueden ser nunca considerados como propios de la arquitectura o de los arquitectos, pero sí del oficio de aquellos que, sin serlos, ejercen como tales; en su mayoría, estarían referidos a los maestros de obras. El arquitecto es quien diseña, el artista intelectual, por eso 


2: artículos David Martín López

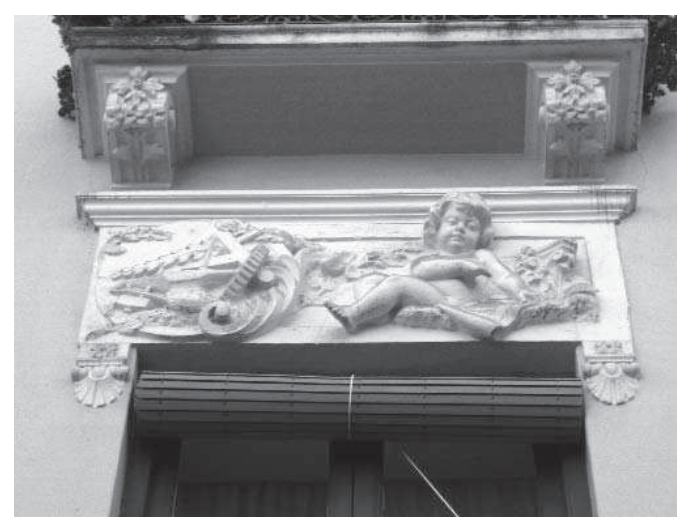

4. JUAN MONSERRAT VERGÉS, Altorrelieve de la casa de Juan Lisbona Granada-Putti con simbología masónica, 1901

Fotografia: David Martín

López.

rel y acacias [4].

Juan Eduardo Cirlot, en su introducción a su obra Diccionario de Símbolos, señala que "al ahondar en los dominios del simbolismo, bien en su forma codificada gráfica o artística, o en su forma viviente y dinámica [...] uno de nuestros esenciales intereses es delimitar el campo de la acción simbólica, para no confundir fenómenos que pueden parecer iguales cuando sólo se asemejan o tienen relación exterior"45. Bien es verdad que muchos de los elementos simbólicos masónicos, no sólo son parte de la masonería, pues provienen de múltiples influencias estéticas orientales, religiosas, gremiales, mitológicas y alquimistas. Pero éstos, bajo la ejecución de un artista masón, que es consciente de su conjunto iconográfico -no ya como el arquitecto culto que es en este caso-, sino de la propia importancia simbólica que adquiere dentro de las logias, perceptible en numerosos grabados y diplomas, no carecen de un sentido explícito y menos de una simbología masónica que pueda ser confundida con otros fenómenos.

A través de los Diplomas de Ascensión de Grado del tinerfeño Andrés Hernández Barrios se puede apreciar el rico repertorio usado en fechas cercanas a la realización del relieve. Este el caso de un diploma elaborado por el Gran Oriente Lusitano Unido -Supremo Consejo de la Masonería Portuguesa- en Lisboa en 1873, con motivo de la ascensión a Grado $18^{\circ}$ Rosa Cruz de Andrés Hernández Barrios.

posee solamente los atributos que le acreditan como tal -compás y cartabón, aludiendo a la geometría-, diferenciándose del maestro que sí posee el nivelador, la escuadra, etc., elementos necesarios para construir el diseño arquitectónico. En la masonería, el compás que representa la espiritualidad somete a la escuadra materialidad-.

45 CIRLOT, J. E.: Diccionario de Símbolos. Madrid, Editorial Siruela, 2004, pág. 17. 


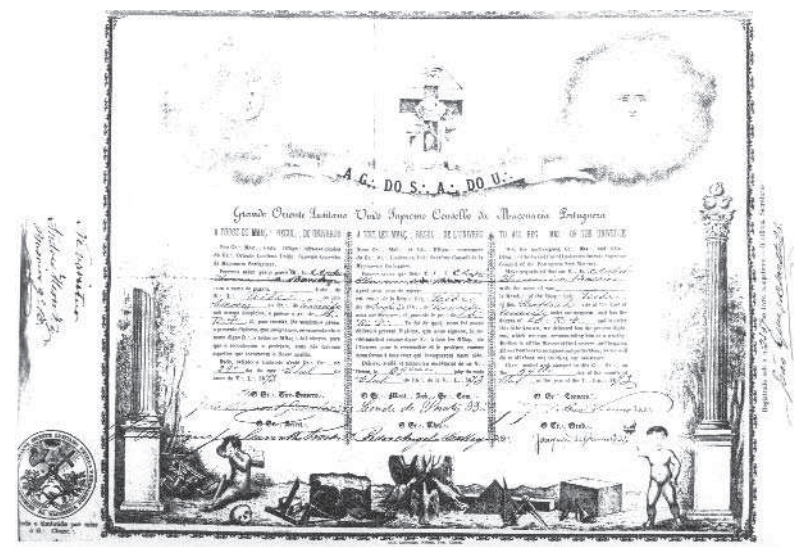

5. Diploma de ascensión a grado $3^{\circ}$ de D. Andrés Hernández Barrios. Taller Justicia de Perú, dependiente del Gran Oriente Nacional. Lima, 1862.

Maestre de por Vida, $20^{\circ}$, del Rito Escocés Antiguo y Aceptado [5]. En él se observan algunos elementos simbólicos que aparecen también en el relieve de Monserrat. El putti alado llora la caída del capitel de la columna -orientada en la misma dirección, y del cual se han caído las tres granadas-, el cartabón, el nivelador, la pala, el pico, los libros, la geometría perfecta de la pirámide y el cubo, aparecen junto al compás 46 .

Aunque no es exactamente la fuente de inspiración de Juan Monserrat para la realización de este relieve, se puede apreciar cómo en unas fechas a finales del

46 Es significativa la evolución de la ubicación e importancia del compás dentro de los diplomas dependiendo del grado de la persona. Si primero es el ajedrezado, como espacio iniciático -que más adelante señalaremos-, luego se sustituye por otros símbolos. El compás se hace cada vez más patente a medida que el Grado aumenta dentro de la masonería. Así, en el diploma de ascensión de D. Andrés Hernández Barrios a Grado $3^{\circ}$ por parte del Taller Justicia de Perú, dependiente del Gran Oriente Nacional, realizado en Lima en 1862. En é, el compás sólo se encuentra en una cartela del basamento de la columna de un pórtico-presentada sobre un ajedrezado-, mientras que, en su ascensión a Grado 200 como Gran Maestre de por Vida- de Rito Escocés Antiguo y Aceptado, dado por el Gran Oriente Lusitano Unido en 1878, el compás toma carác ter de símbolo predominante, de tal modo que es representado sobre un libro en la parte inferior y central de 
s. XIX, el lenguaje iconográfico de la masonería española había adquirido numerosos elementos sincréticos, desde los motivos orientales hasta los gremiales y cristianos. Monserrat hace uso de las hojas y la flor de la acacia en algunas de sus ornamentaciones vegetales, como las de la casa de Buen Suceso. La acacia es el símbolo masónico por excelencia referido a la inmortalidad del alma, debido a su verdor renovado y persistente, habitando en medio de las arenas desérticas: "En la doctrina hermética, simboliza el testamento de Hiram, que enseña que 'hay que saber morir para revivir en la inmortalidad' [...] Con el significado concreto de esta simbolización, del alma y la inmortalidad, se encuentra en el arte cristiano, particularmente en el románico" 47 .

En ocasiones se ha planteado este altorrelieve como una alegoría que representa la dignificación de la arquitectura, circunscrito a la Gran Vía de Colón y a un nuevo panorama económico de una Granada que despunta de Andalucía Oriental, con las incipientes industrias azucareras asociadas a las familias burguesas -como los Giménez Arévalo que apuestan por la construcción de la misma, dentro de la propia sociedad promotora de las obras junto con el Presidente de la Cámara de Comercio de Granada, Juan López-Rubio-. Este es el caso de Francisco Giménez Arévalo, ingeniero industrial vinculado al azúcar, quien proyecta dos singulares edificios para su familia en la Gran Vía de Colón. El primero -núm. 12-, de corte eclecticista, fue proyectado en 1904. El segundo -núm. 27-, es realizado en 1906, con una línea intermedia entre "[...] Historicismo y Modernismo, sobre todo en la hojarasca en relieve de sus miradores, a la que hay que añadir en el mismo estilo indeciso sus barandillas metálicas"48. Ambos incorporan en fachada la misma cartela que, tres años y cinco años antes -respectivamente-, Juan Monserrat Vergés había planteado en Buen Suceso49.

La iconografía masónica que tiene en esta calle, deja tal vez de serlo en la posterior reutilización del relieve en la Gran Vía, dato que desconocemos pues las

diploma (FIG. 6). Cfr. imágenes de los diplomas de Andrés Hernández Barrios. PAZ SÁNCHEZ, M.; CARMONA CALERO, E.: Op. Cit., págs. 153-155

47 CIRLOT, J. E.: Op. Cit., pág. 65.

48 VILLANUEVA MUÑOZ, E. Á.: Ciudad y arquitectura modernista en la Andalucía Oriental. En HENARES CUÉLLAR, I.; GALLEGO ARANDA, S. (eds.): Arquitectura y modernismo. Del historicismo a la modernidad., págs. 221-243 y pág. 233.

49 El edificio más antiguo de los dos -actualmente núm. 12- de la Gran Vía, hace esquina con la calle Cetti Meriem, presentando una fachada eclecticista, como la mayoría de las construcciones de la calle, aunque con una cenefa en el techo del portal y una pintura, que "[...] de ser contemporánea del resto del edificio, con una cenefa en el techo del portal y una pintura, que "[...] de ser contemporánea del resto del edificio,
sería la aproximación más antigua al Art Nouveau[...]" de Granada. VILLANUEVA MUÑOZ, E.: Op. Cit., pág. 232. La pintura está firmada por R. Latorre, sin fecha aunque coetáneo al arquitecto. En el relieve escultori-
co se conserva el compás integro. Rafael Latorre es un pintor que trabaja por esas fechas en Granada, a co se conserva el compás íntegro. Rafael Latorre es un pintor que trabaja por esas fechas en Granada, a de Granada, expuso en él en numerosas ocasiones a lo largo de su vida junto con Gómez Mir, Ruiz de Almodóvar, entre otros -Cfr. ALONSO GÓMEZ, J.: La vida del Centro Artístico. Segunda parte (de 1908 a 1923). Granada, sin fecha. 
Q artículos Juan Monserrat Vergés: Masonería y arquitectura...

fuentes documentales, que han sido objeto de tesis doctorales, sólo han abordado el panorama de la Granada masónica hasta el s. XIX, no figurando ninguno de los miembros de la familia de Giménez-Arévalo. No obstante, no debería ser interpretada como alegoría del arquitecto ni siquiera en las residencias del propio autor que lo incorporan en su domicilio de la Gran Vía y en el de su hermano, ya que los elementos que se representan no corresponden a la arquitectura propiamente dicha, puesto que constan en el relieve otros que son ajenos a la geometría -yunque, maza, palay que sí hablan de la maestría de obras, del artesanado y del componente gremial de la masonería.

Asimismo, Juan Monserrat Vergés adecenta el zaguán de la entrada a la casa de Juan Lisbona, colocando el tradicional ajedrezado marmóreo en blanco y grisáceo oscuro, tan propio de estas tierras desde el s. XVI -como elemento del ritual y la arquitectura cristiana, apreciable en Andalucía con anterioridad-, pero que dentro la masonería adquiere un significado especial apreciable en diplomas masónicos [6], entendido siempre como preámbulo al gran templo -en este caso, el hogar-. El ajedrezado o damero masónico, tanto en blanco y negro como en rojo y blanco, se hace perceptible en otros lugares de especial relevancia para la masonería universal, que no forman parte de una estética tradicional. Son los casos de la arquitectura masónica de Estados Unidos -con la historicista Gran Logia de Filadelfia-, los barrios burgueses decimonónicos de Londres ${ }^{50} \mathrm{o}$ algunas residencias y jardines de las Islas Canarias ${ }^{51}$, así como la singular plaza del Ayuntamiento de la Villa de La Orotava ${ }^{52}$.

50 En Inglaterra, principalmente se pueden ver ajedrezados, con pequeños mosaicos, como solución de pavimento en los accesos desde la calle a los porches de entrada, sobre todo en los barrios originales del s. XIX -Knight's Bridge y Notting Hill, entre otros-

51 Dos ejemplos importantes de ajedrezado en Canarias se encuentran en Tenerife. El primero de ellos, realizado en el final del s. XIX, en la mansión de uno de los más representativos conjuntos masónicos de España: el Mausoleo de la Quinta Roja en La Orotava, obra del arquitecto masón Adolphe Coquet (1841-1907) en 1882. En el zaguán de entrada a la mansión del s. XVIII se interviene en el s. XIX cambiando su enlosetado de piedra por un ajedrezado -blanco y negro-, seguramente bajo idea del propio Marqués de la Quinta Roja. Para una detallada información sobre el Mausoleo de la Quinta Roja: Cfr. GONZÁLEZ LEMUS, N: RODRÍGUEZ MAZA, J. L.: Masonería e intolerancia en Canarias, el caso del Marquesado de la Quinta Roja. Sevilla, Ediciones Benchomo, 2004.

52 En la misma población de Tenerife -La Orotava- existe otro conjunto masónico de excepcional magnitud que presenta ajedrezado: La Plaza del Ayuntamiento. Se trata de la finalización del conjunto del Palacio Municipal iniciado en 1869 -en cuanto se refiere a la casa consistorial- por Pedro Mafitotte, y continuado por el primer Arquitecto Provincial de Canarias, Manuel de Oraá, en 1891. El director técnico de todas las obras era el masón de la logia Taoro ${ }^{\circ}$ 9, Nicolás Álvarez Olivera -PAZ SÁNCHEZ, M.; CARMONA CALERO, E.: Op. Cit., págs. 88-89-, quien ejecuta en 1901 el diseño para la decoración del Salón de Sesiones, obra de Cayetano Fuentes González -HERNÁNDEZ GONZÁLEZ, M.: Tenerife. Patrocinio histórico y cultural. Tenerife, Editorial Rueda, 2002, pág. 169-. En 1907, a la muerte de Nicolás Álvarez Olivera, su hijo Diego Álvarez Editoria Ru (1878-1954) Casanova (1878-1954) -LUQUE HERNANDEZ, A.: La Orotava. Corazon de Tenerife. Tenerife, Excmo. Ayuntamiento de a Villa de La Orotava, 1997, págs. 477-478- ejecutará la finalización de la Plaza, con el ajedrezado simbólico, bajo proyecto de 1911, de Mariano Estanga y Arias- Girón, Arquitecto Provincial de Canarias. Nicolás Álvarez también había intervenido en Mausoleo del Marqués de la Quinta Roja, Don Diego Ponte del Castillo -HERNÁNDEZ GONZÁLEZ, M.: Op. Cit., pág. 172. La excepcionalidad de la plaza radica, no sólo en estilo y modernidad a nivel urbanístico, sino a nivel de la simbolización de todo su entorno filantrópico, rematándose el Ayuntamiento con un frontón con el escudo de La Orotava, la alegoría de la Justicia, la 


Q: artículos David Martín López

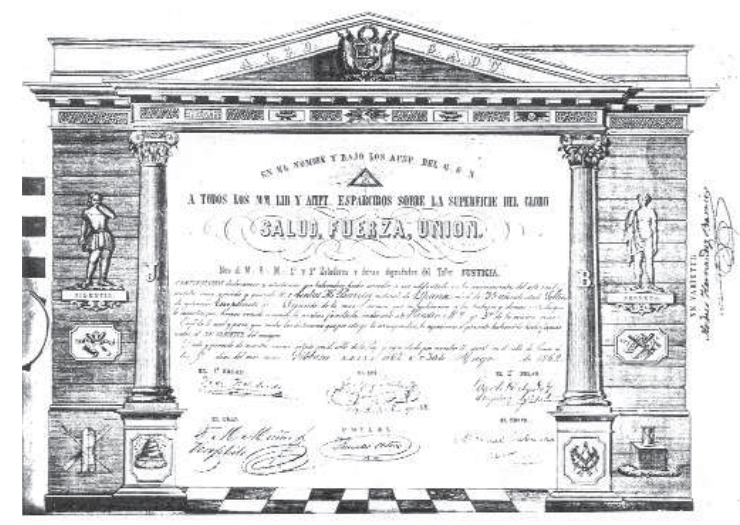

6. Diploma de ascensión a Grado $18^{\circ}$ o Rosa Cruz de D. Andrés Hernández Barrios.Otorgado por el Gran Oriente Lusitano Unido. Lisboa, 1873.

El sistema ortogonal blanco y negro representa, en el ritual masónico, la diversidad de seres, tanto animados como inanimados, que decoran y ornamentan la creación. Este pavimento puede encontrarse en el interior del templo, ya sea de forma permanente, como pavimento o como alfombra ritual en su suelo, y -además- en el hall o zaguán de entrada de muchos de los edificios masónicos.

A modo de conclusión de esta aproximación a la obra de Monserrat Vergés, debemos señalar que la casa de Don Juan Lisbona Beltrán constituye una de las reformas de fachada más singulares en la Granada de principios del siglo pasado 1901-. Su planteamiento totalmente externo y clarividente -incluso, para los no inicia-

Agricultura, la Historia y la Enseñanza -obra de Mariano Estanga, patrocinada por Nicandro González Borges en 1912-. La plaza es entendida como preámbulo iniciático al espacio del Gran templo del pueblo, donde reside el poder local -Ayuntamiento-, ornamentándose con el enlosetado masónico, algo inusual para España al tratarse de un espacio público y político- y además adoptando flores de loto en los bancos y acacias en sus farolas modernistas. 
Q artículos Juan Monserrat Vergés: Masonería y arquitectura...

dos contemporáneos en la masonería, de una estética masónica que será llevada, más tarde, a dos edificios paradigmáticos del modernismo granadino, justifican tanto la razón del texto y la intención del arquitecto.

Nuestro arquitecto se sincera por tanto, ante el viandante y ante el propietario, como artista orgulloso de pertenecer a la Fraternidad masónica. Sin ningún tipo de remordimiento estilístico, reinterpreta un proyecto firmado ya por la Comisión de Ornato, y que había oscilado desde un neomudéjar a su actual planteamiento: una sobria reutilización de recursos, como algunas ménsulas y claves vegetales para los vanos, compensando esta falta de "originalidad" -en el sentido de exclusividad de los medios y materiales constructivos-, con el altorrelieve del dintel de la puerta del balcón central, todo un canto a la filantropía masónica que Monserrat profesa, empleándolos por primera vez en la ciudad granadina, antes que fueran reutilizados por dos de las residencias proyectadas por Francisco Giménez Arévalo en la Gran Vía de Colón.

Tal vez incluso, de forma subversiva a esa Comisión de Ornato municipal, nuestro arquitecto no planteó ciertas pautas estilísticas, pues éste iba a ser firmado por Modesto Cendoya, su sustituto en el cargo municipal y no adscrito a la masonería política ni cultural ${ }^{53}$ de la ciudad. Juan Monserrat, encontrándose más libre de toda ocupación institucional por esas fechas, muy probablemente, no le importara aunar sus dos grandes pasiones de manera un tanto peculiar en el relieve escultórico. Para un arquitecto masón, ilustrado y finisecular, donde el historicismo y los eclecticismos neogóticos eran los estilos modernos en esas fechas, el aludir iconográfica y estéticamente -bajo esas pautas o las apreciables en este inmueble- al Gran Arquitecto o Divino Hacedor - aunándose así, y de manera sincrética, el arte con el componente gremial de la masonería-, tendría que constituir una reafirmación social y cultural de su adscripción filantrópica, que debe ser desencriptada a través de la cientificidad de los estudios históricos y artísticos.

53 Aunque no aparece reflejada la adscripción a la masonería de Modesto Cendoya, sí participa como socio del Centro Artístico Literario y Científico de Granada, siendo nombrado profesor de Modelado. 
